\title{
Do Group Persons have Emotions - Or Should They?
}

Szanto, Thomas

Published in:

Analytical and Continental Philosophy: Methods and Perspectives

DOI:

10.1515/9783110450651-018

Publication date:

2016

Document version

Peer reviewed version

Citation for published version (APA):

Szanto, T. (2016). Do Group Persons have Emotions - Or Should They? In S. Rinofner-Kreidl , \& H. A. Wiltsche (Eds.), Analytical and Continental Philosophy: Methods and Perspectives: Proceedings of the 37th International Wittgenstein Symposium (pp. 261-276). De Gruyter. Publications of the Austrian Ludwig Wittgenstein Society New Series Vol. 23 https://doi.org/10.1515/9783110450651-018 


\title{
Do Group Persons have Emotions-or Should They?
}

\author{
Thomas Szanto
}

\section{Introduction}

Group persons, if there are any, are not made of flesh and blood. Can they, nonetheless, have an emotional life of their own? But why should they in the first place? And what if they cannot? Are, then, group persons only 'soulless', 'fictional' entities, as the Scholastics already declared (Kantorowicz 1957), or some robotic, or 'artificial' person, as Hobbes would later famously put it? Finally, do corporate entities, which lack certain affective abilities necessary for moral conduct, moral address or accountability, such as fellow feelings or sympathy, exhibit psychopathic behaviour (Bakan 2004)? These are the questions I wish to address in this article. I should note here that, although I do not intend the title of this paper to be taken simply as a rhetorical question, I will not offer any conclusive answer to it either. What I wish to do, instead, is to think more seriously about the conditional: what kind of ontological and normative conception of group personhood would result if we either accepted or rejected the view that group persons have emotions.

I will first do so by sketching the contemporary socio-ontological and moralphilosophical discussion on group personhood and showing how, surprisingly, almost none of the available accounts pay any attention to the question of whether emotions, of some sort, may be attributed to group persons (section 2). I will then explore the most important reasons that could motivate such an attribution (section 3), and conclude by replying to the two most apparent reasons that could militate against such an attribution (section 4).

To get an initial flavor for the issue at stake, consider the following type of statements that we can regularly encounter in the media: 'G.M. is concerned about the steep rise of oil prices'; 'Germany deeply regrets the war crimes committed in Greece.' Such statements have also been recently analyzed by a number of authors working on collective emotions (e.g., Gilbert 2002; Tollefsen 2003; Huebner et al. 2010; Huebner 2011; Gilbert 2014; Schmid 2014). No matter how 
one specifies their subject (as legal, artificial, etc.), such statements are not only attributed by third parties but are often also self-attributed, as in the following self-promotion issued by a computer company: "HP is a firm where one can breathe the spirit of interrelations (...). It is an affective relationship" (cited from Illouz 2007, 22).

Now, it seems little contentious that the mental or psychological states attributed in such sentences or self-ascribed in the above statements are emotions or affective states (regret or worrying), or are laden with some emotional import (being concerned about). Moreover, many today would agree that these and many similar statements have group or corporate persons as their subjects. Let's, then, take a closer look at the current discussion.

\section{Mapping the Contemporary Landscape}

In the past few decades, a number of philosophers working on the metaphysics of personal identity have raised the question whether individuals can integrate into a single personal unit that differs from ordinary, human-sized persons (Parfit 1986, 211; Korsgaard 1989; Rovane 1998). The issue of group personhood has also been considerably fuelled by debates on collective intentionality and group agency (see references below). ${ }^{1}$ Further, in times of ever more concentrated corporate power, one can witness a growing interest in the respective normative and political questions. For example, some have inquired whether we have proper obligations towards group persons, or whether they have, above and beyond moral accountability (French 1979; Manning 1984), any moral or political rights of their own, such as the right for protection, the right to persist, or the right to freedom of speech (Ozar 1985; Stoll 2005; List \& Pettit 2011; Briggs 2012; Hess 2013; Hindriks 2014; Kusch 2014). ${ }^{2}$

Unsurprisingly, there is no consensus regarding what properties, rights or obligations entities must bear in order to count as persons, or what the necessary and sufficient conditions of individuating persons are. A number of proposals have been made, which often enough either confound or else deliberately mix cognitive or rational properties and practical, deliberative, or agential, as well as moral, faculties. The situation is not much different when it comes to group persons (henceforth GP). Beyond merely legal, business ethics, and sociological or

\footnotetext{
${ }^{1}$ See Szanto 2015a and 2015b for a phenomenological reassessment of the current discussion.

2 This is particularly pertinent after the 2010 Citizens United v. Federal Election Commission US Supreme Court ruling, according to which corporations are entitled to free speech rights under the First Amendment; see: http://www.supremecourt.gov/opinions/09pdf/08-205.pdf, cf. Hess 2013.
} 
political theory conceptions of corporate personhood, ${ }^{3}$ in the barest outline, we may discern the following four main types of socio-ontological GP-construals in the current literature: ${ }^{4}$

(1) The Moral Address and Moral Agency Attribution Account. Though ontologically there are no proper GP (or, alternatively, whether or not there are such), a collective $C$ can, and in fact should, be counted and treated as a GP, if C is the appropriate target of moral address. Thus, if (i.) C's morally relevant joint action is irreducible to a subset of or the aggregation of the individual members' actions, and if (ii.) either the moral practice of attributing (collective) responsibility to $\mathrm{C}$, or the interpersonal practice of entertaining so-called reactive attitudes (à la Strawson 1968), such as resentment, gratitude, forgiveness, blame, etc., towards $C$, are justified, then $C$ should be treated as a (characteristically personal) subject bearing moral agency, accountability and responsibility (Finnis 1989; Tollefsen 2003; Graham 2004; see also with slightly different emphasis, Manning 1984; Sheehy 2006; Huebner 2014; cf. Hess 2013).

(2) The Moral Personhood Account: Certain groups and corporations are, ontologically, proper persons, if they are intentional and moral agents who are licensed by having a “Corporation's Internal Decision Structure' (CID). CID is a "responsibility flow chart" that, together with certain corporate decision rules embedded in corporate policies and recognized as such, determines the levels of, and ratification, exercise, and control of agency within, a corporation's power structure (French 1979).

(3) The Collective Self-Concept Account. A collective has "person-like properties", such as the capacity to intend, act, plan, regret, or hope, if its members take a first person plural perspective and have a "shared self-concept" (which also includes membership-criteria and is common knowledge among members) (Mathiesen 2003).

(4) The Unity of Rational Agency and Social Integrate Account: A collective qualifies as a group person if it is a unified intentional agent that has its own "rational point of view" (Rovane 1989), from which it deliberates, and which guides its actions and the formation of new beliefs and commitments, and that may well be discontinuous with the rational or "deliberative standpoint" (Korsgaard 1989) of each and every member of the group. Moreover, such

\footnotetext{
3 Think of the most influential types such as the 'realist', the 'fiction' or the 'legal aggregate' theory of corporate entities; cf. French 1979; Hager 1989; Bratton 1989; Runciman 1997. From the veritable industry of historical systematic legal- and political-scientist treatments on this issue, see Dan-Cohen 1986; Mark 1987; Hirst 1989; Blumberg 1993; Ireland 1996, and Wendt 2004.

${ }^{4}$ Consider that the issue whether persons, qua social beings, are part of our social ontology is, though obviously related, orthogonal to the issue of whether that ontology includes group persons; for a positive recent argument of the former issue, see Baker 2015.
} 
“social integrates" (Pettit 2003) can be collectively held (morally) responsible for the failure to rationally unify or integrate their actions and beliefs (see also List \& Pettit 2011; Szanto 2014).

Clearly, these are not incompatible accounts. On the contrary, as should strike the reader obvious, there are various interrelations between them, and especially between (2), (3) and (4). One may also lay the emphasis on some other typical properties of personhood that distinguish corporate persons, such as voluntariness of association, remorsefulness for moral transgression, openness and answerability (Scruton 1989), or 'conversableness' (Pettit 2003; Pettit/List 2011). Notice also that only (1) represents a sort of (Dennettian or Davidsonian) 'interpretationism' that, despite taking the attribution of (moral) personhood to collectives to metaphysically be an open question, or to be unjustified even, still sees it as necessary for normative and explanatory reasons (cf. Tollefsen 2003). All other accounts grant collectives the proper metaphysical status of being persons. There are also some possible intermediate positions between (1) and (2): e.g., one may hold that GP are, though moral agents, no full-fledged persons, because they have no fullfledged moral (but only conventional, or collectively accepted) rights (Ozar 1985). Alternatively, one may hold that the important question is not metaphysical but, rather, whether groups ought to be treated as individual moral persons, and whether we should have the same scruples about being fair to them or holding them morally responsible as we do in the individual case (Manning 1984; see more below, sec. 4).

Meanwhile, there is very little explicit opposition to the attribution of personhood to collectives-which is curious enough, given that, even among rather hard-boiled realists about group agency, there is only a handful who are, however scarcely, willing to make such attributions explicit. 5 Those who explicitly argue against GP typically deny (1) to (4) altogether, doing so either precisely on the ground that collectives are not moral agents (Ranken 1987), and hence not persons or, conversely, that they are not persons, and hence are proper bearers of neither moral rights, nor agency (cf. Wellman 1999). Finally, we have those who-by explicitly distinguishing between a bearer of moral rights, moral agency, and personhood-either claim that, though corporate entities are not persons, and hence have no moral rights proper, they do 'inherit' all necessary properties of moral agency from the respective individuals (Neuhäuser 2011), or that they are full-fledged rational, intentional and moral agents, but still not proper persons, because personhood entails some further properties that collectives lack, notably

\footnotetext{
${ }^{5}$ For a typical example of a realist about group agency and anti-realist about group personhood, see Tuomela's "non-entity view" of group agents: "Groups are not persons, because they have neither bodies nor minds" (Tuomela 2007, 145). Notice that this is all Tuomela has to say on group personhood.
} 
emotions, affectivity, or the capacity to experience vulnerability (Hess 2013; cf. Manning 1984).

In any case, notice the almost complete lack of emotional attribution to GP. Thus, I am not aware of a single author who would explicitly attribute emotions or affective sensitivity to GP, including, notably, those social ontologists who indeed argue for shared, collective or corporate emotions (e.g., Salmela 2012; Gilbert 2014; Schmid 2014). Indeed, I only know of a single author who has directly argued against GP's being persons precisely on the grounds that they do not exhibit any emotional vulnerability or sensitivity (Hess 2013). (I come back to that in sec. 5 below.) Conversely, I know of only one prominent argument in favor of GP, but it still conceives of GP as lacking sensitivity, in any personhooddefining sense (Rovane 1998). Incidentally, this almost complete ignorance fairly reflects a much broader tendency in the philosophy of personhood: the question whether, and in what sense, personhood requires emotions or affectivity has hitherto been paid quite generally very little attention. ${ }^{6}$

\section{Why get Emotional about Group Persons?}

At this point, skeptics, however, might raise the following general concern: why should one pursue the task of attributing emotions to GP, or even just raise this issue, in the first place? After all, both the issue of group personhood and that of collective emotions are contentious enough when discussed separately. Linking these two issues will, so the worry might go, make things even more contentious rather than resolve anything. So why bother about whether groups or corporate entities have emotions? I contend that there are a number of reasons for raising the issue, independently of whether we ultimately attribute emotions to GP.

(1) First, consider how our conception of what it is to be a person is deeply entangled with our conception of what it is to be a subject that has an emotional life. This (intuitive) conceptual entanglement obtains even if, as mentioned, philosophers, rather curiously, remain almost completely silent on spelling out exactly this connection. ${ }^{7}$ This is especially apparent when it comes to moral psychology - and I shall come back to that in a moment-but I think that the conceptual entailment between emotional sensitivity and personhood is not limited to moral emotions, such as shame, forgiveness, indignation, or pride (Steinbock 2014, 274-

\footnotetext{
${ }^{6}$ Notice that, in this paper, I cannot dwell upon any rational, normative, or any other nonemotional, general requirements that an adequate theory of GP must fulfill; I have done so in Szanto 2015c, where I elaborate on what I label 'plurality', the 'integrity', 'normativity, or moral accountability' and 'anti-collectivism' requirement respectively. Against this backdrop, the present paper is an attempt to get clearer about whether we need a further requirement concerning some emotional capacities (see next sec.).

${ }^{7}$ See, however, authors in the phenomenological tradition, and above all Scheler's work (e.g., 1926), but also that of Amelie Rorty (e.g., 1978).
} 
275). But our web of emotions not only defines human subjectivity and, in large part, an individual's personality, or her moral or non-moral character (Rorty 1978; Solomon 1993, 70f.; Ben-Ze'ev 2000, 150-157; Goldie 2000, 141-175). It is our affective dispositions and abilities, their assessment and their education, or our very sensitivity and emotional vulnerability that also lie at the heart of what it means to be a person. Moreover, it is shared focuses of import that define many human communities. Without any emotional import, concern or care, not only would there be no romantic couples, no fan clubs, religious communities, reading clubs, but most natural communities, like families, would also lose much of their cohesive power. (To be sure, not all such communities are, or act as, GP, but some, arguably, do, e.g., a fan club that 'personifies' itself in choosing a spokesperson). As Goldie writes about the connection between emotions and what he aptly calls the "personal point of view", which is opposed not to the objective, third-personal but, rather, to an "impersonal" one: "our ordinary everyday thought and talk about the emotions and emotional experiences is essentially from the personal point of view" (Goldie 2000, 3; cf. 82f., 181ff.). Surely, thishowever essential or constitutive-connection between emotions and persons does not per se license the inference that all types of persons necessarily have emotions; having said this, however, our options seem, intuitively, limited to either of the following alternatives: (a) if we are reluctant to consider seriously the option of attributing some collective or corporate emotions to GP, we should a.) either stop talking of group persons (in which case, i.e., if we are reluctant to posit any GP in our social ontology, it may be better not to employ the talk of collective emotions at all); (b) or we should reassess our notions of (reactive) emotion and personhood altogether, and devise a theory according to which these two personhood and emotional properties may fundamentally come apart, as, so the suggestion might go, they do in the collective case.

(2) Now, whatever psychological or metaphysical theory of personhood or GP we employ, and however emotions factor in there-I believe the single most important reason to attribute emotions to GP is due to the moral address account and, in particular, to the role reactive attitudes play therein (cf. also Tollefsen 2003; Helm 2008; 2014). Incidentally, a large number of authors today consider reactive attitudes to be definitive of moral agency and responsibility in the individual case, too (cf., e.g., Vargas 2013).

First, it may be argued that reactive attitudes need emotions to reliably track them, or to have some morally motivational power, even if this turns out to be a contingent fact of human (moral) psychology. Mele has put this point nicely:

"Perhaps, owing to our basic psychological make up, we simply cannot learn to regard the interests of others as at all important unless we are sensitive to emotions of other people [...] and learn to see ourselves as apt targets of some reactive emotions. Perhaps such sensitivity and learning are, for us, psychologically necessary for 
the acquisition of any sort of moral sensitivity or understanding. This is a contingent matter. [...] Might a hypothetical, isolated community of emotionless beingshence, beings with no reactive attitudes-include morally responsible agents?" (Mele 2000, 449f.)

The idea here is that, if you weren't able to feel ashamed when being blamed, you wouldn't be able to be subjected to reactive attitudes such as blame either, nor would you be able to see when it is appropriate to blame somebody else; moreover, we wouldn't know when and why it would hurt somebody else to be blamed (unjustly or not). It is also this emotional-cum-moral sensibility, and indeed sensitivity, that we both draw upon and try to modulate when we educate the interpersonal behaviour of our children. Now, there seems to be no principled reason why such moral-cum-emotional sensibility should not be possible and, indeed, appropriate in the collective, or group-personal, case.

Secondly, one might conjecture that such a sensibility would allow to faster or more efficiently track the appropriateness of certain actions vis-à-vis certain corporate values than would highly complex corporate decision making procedures (cf., Schmid 2014). In fact, in the individual case, it has been argued that emotions facilitate more intuitive, effortless, and more creative cognitive processes, though, unsurprisingly, often at the detriment of cognitive control and vigilance (Kahneman 2011, esp. 67-70, 137-145).

But let's set aside for a moment these points about moral motivation, and our contingent cognitive psychology. There is, thirdly, another systematic argument for a structural link between emotions and reactive feelings, or attitudes, that remains. It is related to the moral-psychological reasons mentioned above, and has to do with the interactive nature of reactive feelings, precisely qua reactive. Thus, we cannot have any reactive feelings or attitudes in a one-way manner. They necessarily require that both parties involved are creatures that are able to form such attitudes and understand what they imply. Moreover, even if they only represent or target moral emotions (guilt, resentment, blame, etc.), and even if they are not necessarily accompanied by bodily changes or bodily feelings ${ }^{8}$, reactive attitudes certainly do require emotional attitudes on the part of the subject whom these attitudes are directed at. For example, blame would be an utterly inadequate reactive emotion towards stones, but it is also inadequate if the person at whom it is directed does not herself feel accordingly in some way or another. For instance, we expect that somebody will feel ashamed or guilty when being blamed, proud, or even embarrassed, but not afraid, when being praised, etc. In other words, what is partly, but essentially so, targeted when we entertain reactive attitudes towards somebody is that the person feels what she does, and how she does, according to certain moral, but also affective, norms and standards.

\footnotetext{
8 See more on this issue below, sec. 4.
} 
(3) Relatedly, to entertain reactive attitudes arguably also requires creatures who have the capacity to exercise empathy and, eventually, sympathy with others, and this capacity, in turn, will require some sort of emotional or affective life. Consider that this claim does not depend on a more specific doctrine according to which empathy is not primarily a cognitive but an affective state, and/or that it requires some affective interpersonal similarity between empathizer and target (Jacob 2011). Moreover, neither does this claim depend on any claims concerning empathy amounting to or presupposing some affective sharing (e.g., Hein \& Singer 2008). Following a number of phenomenologists (e.g., Zahavi 2011, 2014), I do not endorse either of these claims (cf. Szanto 2015c). The point I wish to make here, however, is more general: arguably, only creatures with some sort or another of an emotional or affective life will be able to empathically experience other emotional creatures, or empathically access and understand what it is to have (any) emotions in the first place; this is also even the case when one empathically understands or sympathizes with specific emotions that one has never experienced (e.g., the grief for the death of another's parents' while one's own are still alive).

At this juncture, one might, of course, object that empathy is not necessary for morality. For example, Prinz (2011) has recently challenged the view that empathy is or even should be viewed as necessary for making moral judgments, for moral development, or even for motivating moral conduct. Consequently, he argues that, in education, socialization, etc., we should not even cultivate any empathy-based morality. Now, Prinz defines empathy, all-too narrowly and ultimately erroneously, in my view, as "a kind of vicarious emotion: it's a feeling what one takes another person to be feeling" (Prinz 2011, 212). But this is not the main issue here. Neither is the moot point that we need empathy in order to share some emotions and eventually sympathize with them. Rather, empathy, understood as the ability to access others' mental and affective states, will be necessary if one wishes to retain the reactive attitude account of (moral) agency. For consider again that reactive attitudes can only have any moral motivation and significance for agents who have the capacity to empathically access, understand, and assess reactive attitudes and feelings (e.g., knowing what it is to forgive, to be blamed, or to feel guilty). But, to repeat, only creatures with some emotional abilities will be endowed with such rich forms of interpersonal understanding.

(5) Lastly-and probably least controversially, but also psychologically and metaphysically least interestingly - in the past couple of decades, one can witness in organizational psychology and management an ever deeper, and 'muddier', entanglement between 'corporate cultures', or the set of norms and values governing companies and institutions, and what is sometimes called 'emotional cultures'. In her intriguing sociological work, Illouz has elaborated this entanglement in terms of what she labels 'emotional capitalism' (Illouz 2007). Consider also in 
this connection a number of organizational studies investigating the correlation between certain negative corporate emotional cultures, such as bullying, unfair supervision or the extreme monitoring of employees, on the one hand, and the presence of so-called 'corporate psychopaths' or 'collective paranoia' (e.g., Kramer 1994; Boddy 2011), on the other. Notice, further, that a corporate emotional culture, if there is any, is not the same as what is sometimes used synonymously with genuinely collective, or group-level, emotions and labeled 'corporate emotions' (e.g., Schmid 2014)

At this point, one will surely want to know what kind of emotions we are actually talking about: what kind of emotions, precisely, are those that might - if at all-be attributed to GP? I can neither dwell upon the exact nature or constitution of collective emotions or the norms governing them, nor on how they might differ either from some less robust forms of emotional sharing, or else from emotional contagion (see Szanto 2015). Instead, against the backdrop of the, admittedly sketchy, considerations so far, I want to suggest the following requirement, call it the Corporate Emotional and Moral Sensibility Requirement, for there being, potentially, any GP-type emotions: ${ }^{9}$

(CEMS) A group person GP may, but will not necessarily, have GP-type emotions if it has a 'shared emotional culture' with a robust evaluative and normative, or 'social appraisal', structure, within or relative to the GP, and if its members have direct perception-based or other mediated mutual awareness of there being such a shared emotional culture. Moreover, members care, or ought to care, for the maintenance of this culture and for the appropriateness of the social appraisal structure vis-à-vis the shared or corporate moral and non-moral values and stances.

\section{Objections and Replies}

Let me close this paper by replying to the two most apparent lines of objection that critics might raise - not so much against this requirement (CEMS) itself but, rather, against any properly group-personal emotions instantiated, provided that CEMS is fulfilled.

The first line of objection to any account of corporate emotions seems to be that GP are not in any straightforward sense embodied agents, and hence cannot be said to have emotions, understood as bodily changes or feelings. There is not much to say to ward off this objection-as long as we take emotions to be reduc-

\footnotetext{
${ }_{9}^{9}$ Again, consider that there are further necessary requirements for there being any GP in the first place (see above, FN 7, and Szanto 2015b). For a more elaborate exposition of the respective natures of the related, but different, shared and collective emotions, see Szanto 2015c, and of social appraisal, in particular, Bruder et al. 2014.
} 
ible to bodily feelings. But such a reduction is surely not mandatory. For one, not only most social psychologists (e.g., Parkinson et al. 2005), but also most philosophers today, and not only emotional cognitivists (e.g., Solomon 1993; Nussbaum 2001), or even those who indeed stress the importance of bodily changes or embodied emotional behaviour (e.g., Damasio 1994; Prinz 2004; Colombetti 2014), would argue for a much richer notion of emotions than one merely involving bodily feelings (e.g., Ben-Ze'ev 2000; Goldie 2000; Roberts 2003; Deonna \& Teroni 2012). Indeed, and more to the point, when it comes to the emotional domain of group persons, the emotions at stake will precisely not be such embodied affective states as, for instance, trembling from fear, but more complex, typically moral, emotions, such as being socially humiliated, not being recognized as a group, or some collective guilt feelings concerning harms committed by one's own group, and the like.

Relatedly, critiques might object that corporate persons cannot, properly speaking, suffer. For example, one might argue that, if a GP is actively 'terminated', or otherwise seizes to exist or, if it is, as it were, put in some painful, or even just some awkward or embarrassing, position, in neither of these cases, if conceivable at all, will GP suffer. Whether or not one, eventually, deduces from this difference between GP and individual persons any differences in their respective rights - as one typically does for persons and animals versus plants or robotsfor some, this difference regarding the vulnerability of human versus corporate persons will seem crucial. Obviously, however, the issue depends on what we take suffering to entail or presuppose. On one reading, suffering is simply associated with some bodily feelings (e.g., physical pain). It is in this sense that some claim that it makes no sense to expand, for instance, the prohibition of (physical and psychological) torture to corporations and group agents (Briggs 2012). We find the most sustained elaboration of this objection in a paper of Hess (2013), in which she argues that corporate entities are, though potentially intentional-cumrational and moral agents, not persons, and in which she appeals to the distinctive (emotional) vulnerability of persons to make her case:

\footnotetext{
"It is our vulnerabilities, as much or more than our powers, that are both distinctive and constitutive of our personhood. It is only because we persons have the specific vulnerabilities that we do-to physical and emotional suffering, to worry and weariness, to humiliation and despair- that we are entitled to or even in need of the specific protections typically granted to us. There is thus no justification for assigning those protections to corporations or anything else that lacks them." (Hess 2013, 335)
}

But, fortunately, there is another reading of vulnerability available than that regarding sheer physical or bodily-affective vulnerability: for it might, just as well, entail moral or some other more complex kind of suffering (apart from, trivially, and particularly so for corporations, financial losses or material suffering). True, 
group persons will, for example, not 'despair' in the exact same ways as individuals; but communities, and by extension, arguably, GP, might very well, for example, be humiliated (cf. Honneth 1994; Copp 2002). Consider a minority that would very well 'despair', namely by having recognition withheld to the point of resorting to terrorism, or one that is humiliated, for instance, by means of one of its members' being publicly ridiculed for her group membership. Or consider an employee who is humiliated qua employee of a given company, or a family, or other strongly cohesive community, who genuinely fears being extinguished or dying out, where this is felt collectively, and for the collective, as a family, or as a minority.

(2) The second line of objection is closely related to the first. According to this concern, emotions and feelings, just like suffering, incidentally, require that the subject who has them has some phenomenal consciousness, or is consciously aware of having them. After all, emotions, and especially their often-invoked 'qualitative feel', seem, in a more straightforward sense than any other type of mental state, ${ }^{10}$ to be paradigmatic examples of conscious states. Moreover, one may, and rightly so, question whether group persons, or group minds, must be collectively conscious or not; indeed, I have argued elsewhere that they need not and, indeed, must not (Szanto 2014). In this vein, for example, Huebner (2011) has voiced similar skepticism. Instead of phenomenally conscious (group)personal level collective emotions, he argues, rather, for subpersonal level collective emotional processes, which may serve similar cognitive functions as individual (and, possibly, personal) level emotions.

But, again, we have a strategy available that allows for reactive emotions to be dissociated from such instances of phenomenal consciousness. According to this, reactive emotions are not individuated by their phenomenology—which GP may then well lack-but, rather, by the norms governing them. Here is how Tollefsen puts this point:

"The fact that collectives lack phenomenology, then, does not mean that they lack the capacity for reactive attitudes. [...] Collective reactive attitudes would be differentiated on this approach from individual reactive attitudes in terms of the norms governing the relevant reactions. Certain emotional responses might be licensed for an individual only because of her group membership. They would also be differentiated in terms of their motivational upshot. The 'pangs' of remorse you feel qua group member may lead you to do actions that you would not do qua individual. Although this approach does not have the collective itself feeling the emotion, it does identify a way in which emotions can be collective. Perhaps this is all we need in order for collectives to be appropriate targets of our reactive attitudes." (Tollefsen 2003, 232)

${ }^{10}$ This is no way to deny or downplay cognitive phenomenology, or the essential correlation, stressed especially by phenomenologists such as Husserl or Sartre, between pre-reflective selfawareness, phenomenal consciousness and the intentionality of mental states; see Szanto 2012. 


\section{Conclusion}

Following this rather cautious move here, and in concluding, let me restate the initial restriction: the argument of the paper should only be understood as a conditional, exploring what would be-descriptively, and, in particular, normatively-gained or lost if we were to attribute a certain sensibility or corporate emotions to group persons. Moreover, let there be no misunderstanding: just as we ought to be as parsimonious as we can in attributing personhood to collectives, so ought we to be very considerate when attributing emotions to group persons. In any case, many types of group agents and collectives, and especially corporations, will be better explained without attributing any emotions to them. They may still pursue goals, or have a rational point of view from which they deliberate or take decisions, even without having a more integrated phenomenal point of view, or focus of import and care. Similarly, we should be more careful in distinguishing different conceptions of personhood when it comes to collectives, just as we should be careful not to see GP where we only have collective emotions, or where we even only have some corporate emotional cultures without any GP. On the other hand, there seems to be little philosophical, or incidentally, normative, reason to be afraid of group persons who may in fact exhibit some form of sensibility - whatever emotional reasons there may well be for being afraid of them.

\section{References}

Bakan, Joel (2004): The Corporation. The Pathological Pursuit of Profit and Power. New York: Free Press.

Baker, Lynne R. (2015): “Human persons as social entities.” Journal of Social Ontology 1(1), pp. $77-87$.

Ben-Ze'ev, Aaron (2000): The Subtlety of Emotions. Cambridge, MA: MIT Press

Blumberg, Philip I. (1993): The Multinational Challenge to Corporation Law. The Search for a New Corporate Personality. Oxford: Oxford University Press.

Boddy, Clive R. (2011): "Corporate psychopaths, bullying and unfair supervision in the workplace." Journal of Business Ethics 100(3), pp. 367-379.

Briggs, Rachael (2012): “The Normative Standing of Group Agents”. Episteme 9(3), pp. 283-291.

Bruder, Martin, Fischer, Agneta, \& Manstead, Antony S. R. (2014): "Social Appraisal as a Cause of Collective Emotions.” In: C. von Scheve, \& M. Salmela (Eds.): Collective emotions, Oxford: Oxford University Press, pp. 141-155.

Colombetti, Giovanna (2014): The Feeling Body. Affective Science Meets the Enactive Mind. Cambridge, MA: MIT Press. 
Copp, David (2002): "Social Unity and the Identity of Persons." The Journal of Political Philosophy 10(4), pp. 365-391.

Damasio, Antonio (1994): Descartes' Error. Emotion, Reason, and the Human Brain. London: Penguin.

Dan-Cohen, Meir (1986): Rights, Persons, and Organizations: A Legal Theory for Bureaucratic Society. Berkeley: University of California Press.

Deonna, Julien A., \& Teroni, Fabrice (2012): The Emotions. A Philosophical Introduction. London/New York: Routledge.

French, Peter A. (1979): "The Corporation as a Moral Person." American Philosophical Quarterly 16 (3), pp. 207-215.

Gilbert, Margaret (2002): Collective guilt and collective guilt feelings. The Journal of Ethics, 6(2), 115-143.

- (2014): "How we feel: Understanding everyday collective emotion ascription." In: C. von Scheve, \& M. Salmela (Eds.): Collective emotions. Oxford: Oxford University Press, pp. 17-31.

Goldie, Peter (2000): The Emotions. A Philosophical Exploration. Oxford: Oxford University Press

Hager, Mark M. (1989): "Bodies politic: The progressive history of organizational 'Real Entity' theory." University of Pittsburgh Law Review 50(3), pp. 575-654.

Helm, Bennett (2008): "Plural Agents." Noûs 42(1), pp. 17-49.

- (2014): "Emotional communities of respect." In: C. von Scheve, \& M. Salmela (Eds.): Collective emotions. Oxford: Oxford University Press, pp. 47-60.

Hess, Kendy M. (2013): “'If You Tickle Us...': How Corporations Can Be Moral Agents Without Being Persons." The Journal of V alue Inquiry 47(3), pp. 319-335.

Hindriks, Frank (2014): "How Autonomous Are Collective Agents? Corporate Rights and Normative Individualism." Erkenntnis 79(9), pp. 1565-1585.

Hirst, Paul Q. (1989): “Introduction.” In: P. Q. Hirst (Ed.): The Pluralist Theory of the State. Selected Writings of G.D.H. Cole, J.N. Figgis, and H.J. Laski. London/New York: Routledge, pp. 1-45.

Honneth, Axel (1994): Kampf um Anerkennung: Zur moralischen Grammatik sozialer Konflikte. Frankfurt a.M.: Suhrkamp.

Huebner, Bryce (2011): "Genuinely collective emotions." European Journal for Philosopby of Science 1(1), pp. 89-118.

— (2014): Macrocognition. A Theory of Distributed Minds and Collective Intentionality. Oxford: Oxford University Press.

Huebner, Bryce, Bruno, Michael, \& Sarkissian, Hagop (2010): "What does the nation of China think about phenomenal states?" Review of philosophy and psychology 1(2), pp. 225-243.

Illouz, Eva (2007): Cold Intimacies. The Making of Emotional Capitalism. Cambridge: Polity.

Ireland, Paddy (1996): "Capitalism without the capitalist: The joint stock company share and the emergence of the modern doctrine of separate corporate personality." The Journal of Legal History 17(1), pp. 41-73.

Kahneman, Daniel (2011): Thinking, Fast and Slow. London: Penguin.

Kantorowicz, Ernst H. (1957): The King's Two Bodies: A Study in Medieval Political Theology. Princeton: Princeton University Press 1997. 
Korsgaard, Christine M. (1989): "Personal identity and the unity of agency: A Kantian response to Parfit." Philosophy \& Public Affairs 18(2), 101-132.

Kusch, Martin (2014): "The Metaphysics and Politics of Corporate Personhood." Erkenntnis 79(9), pp. 1587-1600.

Kramer, Roderick M. (1994): "The Sinister Attribution Error. Paranoid Cognition and Collective Distrust in Organizations." In: Motivation and Emotion 18(2), pp. 199230.

List, Christian, \& Pettit, Philip (2011): Group Agency. The Possibility, Design, and Status of Corporate Agents. Oxford: Oxford University Press.

Mathiesen, Kay (2003): “On Collective Identity.” Protosociology 18-19, pp. 66-86.

Manning, Rita C. (1984): "Corporate Responsibility and Corporate Personhood." Journal of Business Ethics 3 (1), pp. 77-84.

Mark, Gregory A. (1987): "The Personification of the Business Corporation in American Law." The University of Chicago Law Review 54(4), pp. 1441-1483.

Mele, Alfred R. (2000): "Reactive Attitudes, Reactivity, and Omissions." Philosophy and Phenomenological Research 61(2), pp. 447-452.

Neuhäuser, Christian (2011): Unternehmen als moralische Akteure. Berlin: Suhrkamp.

Nussbaum, Martha C. (2001): Upheavals of thought: The intelligence of emotions. Cambridge: Cambridge University Press, 2003.

Ozar, David T. (1985): "Do corporations have moral rights?” Journal of Business Ethics 4(4), pp. 277-281.

Parfit, Derek (1986): Reasons and Persons. Oxford: Oxford University Press.

Parkinson, Brian, Fischer, Agneta H., \& Manstead, Antony S. R. (2005): Emotion in Social Relations. Cultural, Group, and Interpersonal Processes. New York: Psychology Press.

Pettit, Philip (2003): “Groups with minds of their own.” In: F. Schmitt (Ed.): Socializing Metaphysics. New York: Rowman \& Littlefield, pp. 167-193.

Prinz, Jesse J. (2004): Gut Reactions. A Perceptual Theory of Emotions. Oxford: Oxford University Press.

_ (2011): "Is Empathy Necessary for Morality?" In: A. Coplan, \& P. Goldie (Eds.): Empathy: Philosophical and Psychological Perspectives. Oxford: Oxford University Press, pp. 211-229.

Ranken, Nani L. (1987). "Corporations as Persons: Objections to Goodpaster's 'Principle of Moral Projection'." Journal of Business Ethics 6(8), pp. 633-637.

Rorty, Amelie Oksenberg (1978): "Explaining Emotions." The Journal of Philosophy 75(3), pp. 139-161.

Rovane, Carol (1998): The Bounds of Agency. An Essay in Revisionary Metaphysics. Princeton: Princeton University Press.

Runciman, David (1997): Pluralism and the Personality of the State. Cambridge: Cambridge University Press.

Salmela, Mikko (2012): "Shared emotions." Philosophical Explorations 15(1), pp. 33-46.

- (2014b): The feeling of being a group. Corporate Emotions and Collective Consciousness. In: C. von Scheve, \& M. Salmela (Eds.): Collective emotions. Oxford: Oxford University Press, pp. 3-16.

Scheler, Max (1926): Der Formalismus in der Ethik und die material Wertethik. Nener Versuch der Grundlegung eines ethischen Personalismus. Bern: Francke 1980. 
Schmid, Hans Bernhard (2014): "The feeling of being a group: corporate emotions and collective consciousness.” In: C. von Scheve, \& M. Salmela (Eds.): Collective emotions, Oxford: Oxford University Press, pp. 3-16.

Scruton, Roger (1989): “Corporate persons." Proceedings of the Aristotelian Society, Suppl. Vol. 63, pp. 239-274.

Sheehy, Paul (2006): The Reality of Social Groups. Aldeshot: Ashgate.

Solomon, Robert C. (1993): The Passions. Emotions and the Meaning of Life. Indianapolis: Hackett.

Steinbock, Anthony J. (2014): Moral Emotions. Reclaiming the Evidence of the Heart. Evanston, Ill.: Northwestern University Press.

Stoll, Mary L. (2005): “Corporate Rights to Free Speech?” Journal of Business Ethics 58(13), pp. 261-269.

Szanto, Thomas (2012): Bewusstsein, Intentionalität, und Mental Repräsentation. Husserl und die Analytische Philosophie des Geistes. Berlin, Boston: de Gruyter.

_ (2014): "How to Share a Mind: Reconsidering the Group Mind Thesis." Phenomenology and the Cognitive Sciences 13(1), pp. 99-120.

_ (2015a): "Husserl on Collective Intentionality." In: A. Salice, \& H. B. Schmid (Eds.): Social Reality. The Phenomenological Approach. Dordrecht: Springer.

_ (2015b): "Collectivizing Persons and Personifying Collectives: Reassessing Scheler on Group Personhood.” In: T. Szanto, \& D. Moran (Eds.): The Phenomenology of Sociality: Discovering the 'We'. London/New York: Routledge.

— (2015c): "Collective Emotions, Normativity, and Empathy: A Steinian Proposal." Human Studies.

Tollefsen, Deborah P. (2003): "Participant Reactive Attitudes and Collective Responsibility." Philosophical Explorations 6(3), pp. 218-234.

Tuomela, Raimo (2007): The Philosophy of Sociality. The Shared Point of View. Oxford: Oxford University Press.

Vargas, Manuel (2013): Building Better Beings. A Theory of Moral Responsibility. Oxford: Oxford University Press.

Wellman, Christopher C. (1999). "Liberalism, communitarianism, and group rights." Law and Pbilosophy 18(1), 13-40.

Wendt, Alexander (2004): "The state as person in international theory." Review of International Studies 30(2), pp. 289-316.

Zahavi, Dan (2011): "Empathy and direct social perception: a phenomenological proposal." Review of Philosophy and Psychology, 2(3), 541-558.

- (2014): Self and Other: Exploring Subjectivity, Empathy, and Shame. Oxford: Oxford University Press. 